\title{
青藏高原夷平面与岩溶时代及其起始高度 *
}

崔之久 高全洲 刘耕年

(北京大学城市与环境学系, 北京 100871)
潘保田陈怀录

(兰州大学地理科学系, 兰州 730000)

\section{关链词高藏高原 夷平面 时代 高度}

青藏高原夷平面形成的时代、性质和原始高度等是解决高原隆升这一世界瞩目课题的关 键. 李吉均等 ${ }^{[1]}$ 指出夷平面在高原隆升的研究中有重要意义. 杨逸畴、李炳元等曾提出高原 上有山原面和盆地面两级夷平面 ${ }^{[2]}$. Shackleton和常承法 ${ }^{[3]}$ 认为仅有一级夷平面 $(4500 \sim$ $6000 \mathrm{~m}$ ), 时代在 $10 \mathrm{MaBP}$ 以前的中新世. 早在 60 年代本文作者之一就认识到古岩溶研究 是高原隆升的有力证据 ${ }^{[4]} .1994$ 年本文作者又根据当时已知数据也撰文指出高原夷平面 (包 括岩溶面) 可以追溯到 $15 \mathrm{MaBP}^{[5]}$, 但由于测年数据有限未能对夷平面性质及原始高度做深入 的讨论.

\section{1 夷平面的级数与分布}

作者依据新获得的有关高原夷平面的裂变径迹年代及其区域分异特点 (表 1), 并结合相 关沉积,认为在整个第三纪期间发育过两级夷平面(表 2).

表 1 青藏高原石灰岩夷平面上洞穴再结晶方解石裂变径迹测年结果 $\left.{ }^{a}\right)$

\begin{tabular}{|c|c|c|c|c|}
\hline 海拔 $/ \mathrm{m}$ & 纬度 $(\mathrm{N})$ & 地貌部位及样本性质 & 采样地点 & 裂变径迹年龄/ $\mathrm{MaBP}$ \\
\hline 4900 & $28^{\circ} 30^{\prime}$ & 近期崩埸的洞穴石堆 & 协格尔(4 900) & $13.38 \pm 1.13$ \\
\hline $\begin{array}{l}3750 \\
3750\end{array}$ & $\begin{array}{l}29^{\circ} 20^{\prime} \\
29^{\circ} 20^{\prime}\end{array}$ & $\begin{array}{l}\text { 山坡洞内 } \\
\text { 山坡洞内 }\end{array}$ & $\begin{array}{l}\text { 曲水大佛北侧 } \\
\text { 曲水大佛南侧 }\end{array}$ & $\begin{array}{r}7.39 \pm 0.65 \\
10.10 \pm 0.86\end{array}$ \\
\hline $\begin{array}{l}3900 \\
4000\end{array}$ & $\begin{array}{l}29^{\circ} 40^{\prime} \\
29^{\circ} 40^{\prime}\end{array}$ & $\begin{array}{l}\text { 山坡洞内 } \\
\text { 山坡洞内 }\end{array}$ & $\begin{array}{c}\text { 拉萨堆龙 } 3900 \\
\text { 拉萨堆龙下 }\end{array}$ & $\begin{array}{l}18.94 \pm 1.63 \\
15.06 \pm 1.30\end{array}$ \\
\hline 4800 & $32^{\circ} 20^{\prime}$ & 山坡洞内 & 安多北山 4800 & $8.86 \pm 0.76$ \\
\hline 3600 & $33^{\circ} 00^{\prime}$ & 山波洞内 & 玉树巴塘 3600 & $15.15 \pm 1.36$ \\
\hline 3600 & $34^{\circ} 06^{\prime}$ & 山坡洞内 & 郎木寺 3600 & $11.68 \pm 0.93$ \\
\hline 3600 & $34^{\circ} 30^{\prime}$ & 近期崩塌的洞穴石堆 & 则岔 3600 & $13.26 \pm 1.05$ \\
\hline 4450 & $39^{\circ} 00^{\prime}$ & 山坡洞内 & 阿尔金山 A-1 & $12.20 \pm 1.03$ \\
\hline
\end{tabular}

a)兰州大学地理系分析测试

1995-10-31 收稿, 1996-01-30 收修改稿

*国家“登”计划和国家自然科学基金资助项目 
表 2 青藏高原中段南北方向上夷平面分布与特征 (沿东经 $86^{\circ} \sim 91^{\circ}$ 往东北至 $90^{\circ} \sim 95^{\circ}$ 之间)

\begin{tabular}{|c|c|c|c|c|c|}
\hline 编号 & 地 点 & \multicolumn{2}{|c|}{ 高度 (m)与级数年) } & $\begin{array}{c}\text { 底面切过最新地层、 } \\
\text { 夏盖火山岩及岩溶年代 }\end{array}$ & 地貌特征 \\
\hline 1 & 线布寺东, 西两侧 & $5900 \sim 6000$ & I & 花岗岩? & 近现代雪线, 发育石海 \\
\hline 2 & 定日东山 & 5500 & II & J. 灰岩 & 古岩溶, 古红色风化壳 \\
\hline 3 & 遮不惹山 & 5500 & II & $\begin{array}{l}\text { 始-渐新统生物灰岩, 拉轨岗口花 } \\
\text { 岗岩 } 10 \mathrm{MaBP} \text {, 岩溶 } 12 \mathrm{MaBP}\end{array}$ & 面上有古岩溶 \\
\hline 4 & $\begin{array}{l}\text { 冈底斯山, 雅鲁藏布 } \\
\text { 江南北岸, 包括拉萨 } \\
\text { 南北山地 }\end{array}$ & $\begin{array}{l}5000 \sim 5700 \\
4500 \sim 5000\end{array}$ & I & $\begin{array}{l}\text { J. 灰岩岩溶 } 19 \sim 7 \mathrm{MaBP} \text {, 捷嗿热 } \\
\text { 帮雄马安山岩年代 }(23.1 \pm 0.3) \\
\mathrm{MaBP}\end{array}$ & $\begin{array}{l}\text { 有的面徣盖火山岩 } \\
\text { 有的面发育古岩溶 }\end{array}$ \\
\hline 5 & $\begin{array}{l}\text { 念青唐古拉山(包括 } \\
\text { 宁金康沙峰) }\end{array}$ & $5700 \sim 6000$ & $\mathrm{I}$ & $\begin{array}{l}\text { 削平片麻岩. 年代 } 50 \mathrm{MaBP} \text { (15 } \\
\mathrm{km} \text { 深处形成) }\end{array}$ & $\begin{array}{l}\text { 大面积平齐山顶面, 近现代 } \\
\text { 雪线有冰斗冰川发育 }\end{array}$ \\
\hline 6 & $\begin{array}{l}\text { 安多南山(安多至那 } \\
\text { 曲间) }\end{array}$ & 5100 & II & $\begin{array}{l}\text { 切平 J. 地层、改则安山岩年代 } \\
10.6 \mathrm{MaBP}\end{array}$ & 整齐夷平面 \\
\hline .7 & 安多北山及罗尔久山 & 5125 & II & J. 灰岩岩溶 $12.2 \mathrm{MaBP}$ & 整齐夷平面 \\
\hline 8 & 唐古拉山 & 5700 & I & 中新世火山岩覆夷平面 & 风化壳或有小冰帽覆盖 \\
\hline 9 & 乌丽山 温泉一线 & 5000 & II & J. 灰岩? & 面上有古岩溶 \\
\hline 10 & 风火山 & 5200 & $\mathrm{I}$ & $\begin{array}{l}\text { 切平中始新世 渐新世红层. 火 } \\
\text { 山岩年代 } 32 \sim 30 \mathrm{MaBP}\end{array}$ & 整齐夷平面 \\
\hline 11 & 可可西里-南昆仑山 & 5600 & & $\begin{array}{r}\text { 粗面岩18 17 MaBP } \\
12 \sim 10 \mathrm{MaBP}\end{array}$ & $\begin{array}{l}\text { 面上有火山岩高盖, 顶面有 } \\
\text { 古岩溶, 年代未知, II 级面 } \\
\text { 古岩溶年代为 } 12.2 \mathrm{MaBP}\end{array}$ \\
\hline 12 & 西大滩北山 & 5100 & II & 花岗岩 $5 \mathrm{MaBP}$ & 顶部为石海, 接近现代雪线 \\
\hline 13 & 纳赤台北山 & 5000 & II & C. 玄武岩, 大理岩 & 顶部有末次冰期冰斗 \\
\hline 14 & $\begin{array}{l}\text { 布尔军布达山 } \\
\text { (中昆仑) }\end{array}$ & $5900 \sim 6000$ & $\mathrm{I}$ & 削平 $\mathrm{T}$ 、红层和 $\mathrm{J}$. 砂岩 & 中新世地层覆于山顶面 \\
\hline
\end{tabular}

a) I 代表老荑平面即山顶面; II 代表较老夷平面即主夷平面

（1）老夷平面 也称山顶面, 多数保留在局部未遭受后期强烈切割的高原内部地区. 高 度在 $5000 \sim 6000 \mathrm{~m}$ 左右, 南低北高. 它在雅鲁藏布江流域两侧为 $5000 \mathrm{~m}$ 左右, 往北在唐古 拉山高度为 $5500 \mathrm{~m}$, 再往北到昆仑山可达 $6000 \mathrm{~m}$. 根据所削平的最新地层、其上覆盖的火山 熔岩及相关沉积, 时代定为渐新世至早中新世.

(2)较老夷平面 也称主夷平面, 高度 $4000 \sim 4500 \mathrm{~m}$ 左右, 分布较老夷平面为广, 宏观 上主要在中部、北部, 各种古岩溶地形就主要分布在这级夷平面上. 有些地方海拔高度随高原 总地势向东有所降低, 如迭部、武都和中甸, 低于 $4000 \mathrm{~m}$, 时代是 $19 \sim 7 \mathrm{MaBP}$ 左右, 多独立存 在而成为当地的最高面 (如郎木寺、武都、则叉、中甸和玉树). 


\section{2 岩溶年代及年代的区域分异特点}

青藏高原夷平面有一部分位于灰岩区, 广泛的夷平作用可不加区别地削平各种岩性的岩 石,故可以用岩溶发育的年代代表同一级夷平面的时代.

据 Young 等对坡地后退速度的推算 ${ }^{[6]}$, 形成夷平面需要长达千万年数量级的稳定构造环 境. 本次研究测得再结晶方解石的裂变径迹年龄 20 个, 时代在 19.0 7.0 MaBP 之间, 说明 较老夷平面应形成于这一时期. 在所测数据中较老的岩溶年代 (15 19 Ma) 在高原南部 ( $33^{\circ}$ $\mathrm{N}$ 以南)和东南部, 较新的岩溶年代 (7 10 Ma) 在高原中部和北部. 高原宏观地貌特点是南 部和东南部的河流发育历史较早, 目前皆为高山深谷区; 中部则多保留原始的地面或作为内陆 湖区和宽广的大河源区, 河流发育历史年轻. 高原西部的资料暂缺. 岩溶发育年代和河流发 育历史的对比表明, 高原岩溶发育史受宏观的河流发育史控制. 同时, 反过来也说明高原东半 部河流在中新世已见端倪, 并和现在格局相似, 主要河流皆从西流向东南.

根据侵蚀循环理论, 夷平面或准平原的形成皆以河流侵蚀为主导, 辅以不同气候条件下的 风化和多种外营力的搬运, 要求气候比较湿润, 水流充沛 ${ }^{[7]}$. 所以, 岩溶发育时, 河流作为创 造夷平面的主要动力也同时塑造了高原较老夷平面.

\section{3 夷平面性质和初始高度的讨论}

据 Budel 双水平面理论 ${ }^{[7]}$, 干湿季分明的热带疏林草原环境下形成的是双层水平面 (Double surface of leveling). 就目前掌握的资料看, 中新世的青藏地区可能类似于这种环境, 至少 南部和中部如此. 目前高原上灰岩地区夷平面上保留的大量岩溶地貌都具有地下覆盖特征, 如石墙、岩柱、穿洞、崖鿖和天生桥等都是. 这说明较老夷平面形成于化学风化作用强烈的环 境, 具有双层夷平面的性质. 作者根据高原东部大河向南、向东流的特点再考虑外围同时期相 关沉积的相特征, 认为高原夷平面似与现在高原地面一样是一个向南、向东的缓倾面, 印度河 流域可能向西倾斜. 总之, 南部海拔低 $(<500 \mathrm{~m}$ ) 而北部(唐古拉山与昆仑山之间) 稍高 (1000 $\sim 1500 \mathrm{~m}$ ), 中间 (冈底斯山与唐古拉山之间) 为过渡区 $(1000 \mathrm{~m} \pm$ ). 只有这种海拔高度低且 各地段只有很小相对高差 $(<100 \mathrm{~m})$ 的平坦地形, 才能保证来自源区的沉积物是以粉砂和粘土 为主. 作者采自下 Siwalik 层样品中的粘土 $(>8 \phi)$ 含量为 $42 \%$, 粉砂 $(4 \sim 8 \phi) 37 \%$, 砂 $(<4 \phi)$ $21 \%$; 中 Siwalik 的粘土含量为 $26 \%$, 粉砂 $58 \%$, 砂 $16 \%$.

中、下 Siwalik 中以粘土、粉砂为主, 砂最少, 表明物质主要来自夷平面上的红色粘土风化 壳; 分选度不高, 表明搬运不远. 说明就近有物源供应, 但不应是山地, 而只是一种和缓的地面 占据了现在尼泊尔的大-小喜马拉雅地段, 源区应是大范围的夷平环境. Siwalik 沉积源区有 可能扩展到现今喜马拉雅和冈底斯之间地区, 甚至唐古拉山以南地区. 因为同一时期在此处 渐新世磨拉石建造之上不整合覆盖着含油页岩和煤层的湖相地层 ${ }^{[8]}$, 所有这些显示了较老夷 平面形成时高度不会很高. 与 Siwalik 沉积相对应, 在高原北部的临夏群中相同时期多次出现 的泥岩层也反映同样的沉积环境 ${ }^{[9]}$. 原始青藏地区具有南低北高的特点, 北部构造抬升强 度、地形高差 (相对和绝对的) 要比南部大. 高原南侧夷平面海拔低, 发育稳定, 所以从 Siwalik 底 (18.3 MaBP) 到 Dhok Pathan 组 (8.5 MaBP) 跨时 $10 \mathrm{Ma}$, 沉积物粒度基本一致, 虽经历 4 次 河流沉积旋回, 但始终缺少粗粒物质. 而临夏群在同一时段 $(21 \sim 7.0 \mathrm{Ma})$ 经历了从砂砾层到 
泥岩层 4 个大旋回. 粒度变化幅度大反映其构造和地形高低的波动幅度比高原南侧大, 夷平 面发育环境不及南部稳定.

此外, 已知岩溶剥蚀面上石墙和岩柱的高度 (即当时覆盖深度) 达 $30 \sim 40 \mathrm{~m}$. 安多北山红 色风化壳中高岭石的含量可达 $34 \%$, 花石峡的红色风化壳根部高岭石含量达 $70 \%$, 这与 Budel 对印度德干高原红色风化壳的研究结果一致, 即由富含高岭石的红色粘土组成 ${ }^{[10]}$.

据古水流分析 ${ }^{[11]}$, Siwalik 碎屑物皆来自北方, 但沉积物矿物组合显示南北皆有贡献. 就 北方物源区而言, 西北方向来源区早于东北方向, 且有随原始高原雏形的出现使物源区逐渐扩 大的特点. 如尼泊尔 Siwalik 层物源区在下 Siwalik 时是来自中部、北部抬升地区, 而中上 Siwalik 则扩大到北方的花岗岩和片麻岩区. 这表明, 横跨高原的大夷平面可能是由不同流域的 分段夷平过程彼此逐渐联合而成,也可能最终并未彻底联通,但确系同属一个夷平面.

除按夷平面发育在理论上不能离侵蚀基准面之一一一海面太高外, 认为高原南部夷平面 高度 $<500 \mathrm{~m}$ 最大不超过 $1000 \mathrm{~m}$ 的其他依据还有: (1) 现代非洲 Sawana 区皆在 $200 \sim 500 \mathrm{~m}$ 左右或略高 (个别高山例外); (2) Hetauda 所采尼泊尔中、下 Siwalik 红色粘土泥岩 (硅铝率 3.32) 和黄砂层 (硅铝率 3.20) 标本处在海拔 $600 \mathrm{~m}$, 现已成丘陵. 当时应象现恒河平原一样, 高度低于 $100 \mathrm{~m}$, 与残留在安多山顶 $(5125 \mathrm{~m})$ 的红土层及其化学成分硅铝率 (3.55)十分近似. 再联系到粒度成分如此之细, 若以 $1 / 1000$ 比降计, 从该处到拉萨地区直线距离为 $500 \mathrm{~km}$ 左 右, 故拉萨地区也即应在 $500 \mathrm{~m}$ 左右; (3) 据作者观测, 靠近赤道的马来西亚 Muli 地区 ( $4^{\circ} \sim 7^{\circ}$ $\mathrm{N}$ ) 的热带岩溶溶洞和覆盖岩溶都集中分布在海拔 $200 \mathrm{~m}$ 以下地区, 再高处如超过 $1000 \mathrm{~m}$ 即 为石林 (似路南石林, 但更尖、更高) 区, 已无覆盖岩溶和塔状、柱状岩溶存在; (4) 按照 Budel 就 德干高原研究结果认为 ${ }^{[10]}$, 可以在地 球上任何纬度和高度找到中新世夷 平面 (直到亚极地). 其实, 在古恒河 平原以北相隔 $300 \sim 400 \mathrm{~km}$ 就有大 面积中新世夷平面一一青藏高原夷 平面存在．现德干高原老夷平面在 400 1 $000 \mathrm{~m}$, 而新夷平面则在 400 $\mathrm{m}$ 以下 $(150 \mathrm{~m}$ 至几十米以至海边). Budel 承认中新世～早上新世德干高 原有抬升, 故原始老夷平面应和现夷 平面相似, 即不超过 $400 \mathrm{~m}$. 当初德 干高原夷平面和青藏高原夷平面似 呈南北呼应之势, 都是外侧高而同时 向恒河平原倾斜, 两面物质皆一部分 汇向老恒河平原以供应 Siwalik 层, 另 一部分则流向他处并最终人海 (图

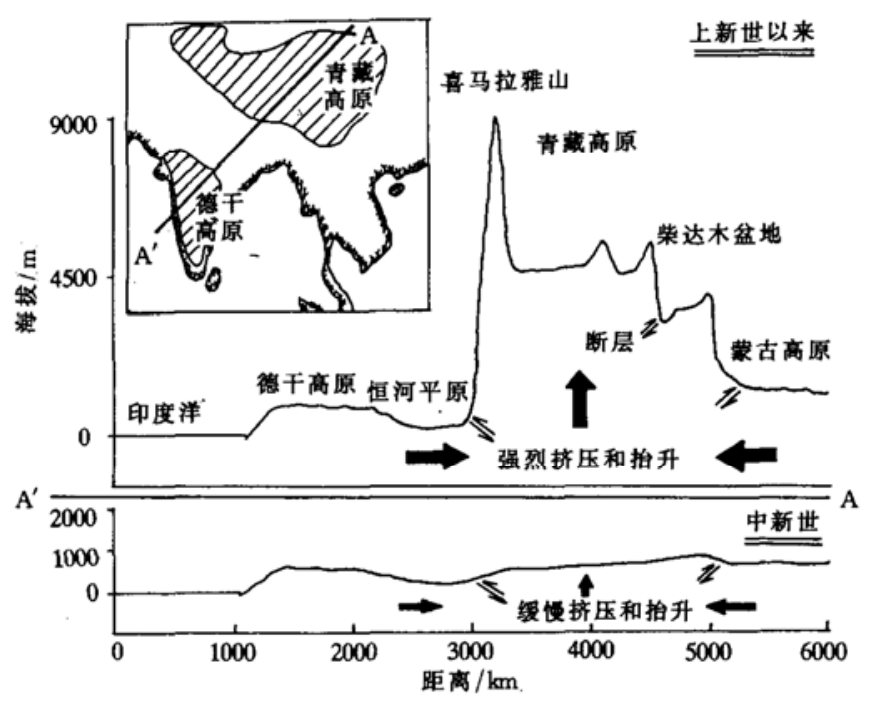

图 1 青藏高原和德干高原晚第三纪夷平面形成演化示意图 1).

致谢本文承施雅风、李吉均先生指导、帮助, 特此致谢. 


\section{参考文 献}

1 李吉均, 文世宣, 张青松等. 青藏高原隆起的时代、幅度和形式探讨. 中国科学, 1979, (6):608 616

2 杨逸捧, 李炳元, 尹泽生等. 西藏地貌. 北京: 科学出版社, 1983. 200 212

3 Shackleton R M, 常承法. 青藏高原新生代的隆起和变形: 地貌证据. 见: 青藏高原地质演化. 北京: 科学出版社, 1990. $372 \sim 383$

4 崔之久, 郑本兴. 珠穆朗玛峰地区的喀斯特. 见: 珠穆朗玛峰地区科学考察报告(1966 1968), 现代冰川与地貌. 北 京: 科学出版社, 1975. 169 179

5 崔之久, 洪云, 陈怀录. 青藏高原古岩溶研究的新进展. 见: 青藏高原形成演化、环境变迁与生态系统研究. 北京: 科 学出版社, 1995. 120 125

6 Young A, Saunders I. Rates of surface processes and deundation. In: Hillslope Processes. Boston: Allen \& Unwin Inc, 1986. $3 \sim 27$

7 Budel J. Double surface of leveling in the Humid Tropics. Zeit Geomorph, 1957, 1(2):223 225

8 王富荣. 青藏高原的喀斯特. 中国岩溶, 1990, 9(3):277 278

9 李吉均, 方小敏, 朱俊杰等. 临夏盆地新生代地层古地磁年代与模式序列. 见: 青藏高原形成演化、环境变迁与生态系 统研究(学术论文年刊). 北京: 科学出版社, 1995. 41 54

10 Budel J. The relief types of the sheetwash zone of southern india on the eastern slope of the Deccan highlands towards Madras. In: Adams G ed. Planation Surface, Benchmark Papers in Geology, V. 22. Dowden, Hutchiason \& Ross Inc, 1965, 367 372

11 Sharma C K. Geology of Nepal Himalaya and Adjacent Countries. New Delhi: Prentice-Hall Inc, 1990, 322 327 